Journal of Risk and Control, Vol.8, No.1, 2021, 19-32

ISSN: 2056-3701 (print version), 2056-371X (online)

https://doi.org/10.47260/jrc/812

Scientific Press International Limited

\title{
Public Health Federalism?
}

\author{
Mitch Kunce'
}

\begin{abstract}
This paper develops a general equilibrium model of competitive jurisdictional choice that provides insights into what is being coined 'public health federalism'. Using a standard neoclassical model of production combined with a utility maximization hypothesis, jurisdictions choose both tax rates and a level of local public health quality. Incorporating the joint determination of both tax decisions and the choice of public health standards can give rise to some interesting interrelationships between local tax revenues and public health considerations. Additionally, the model is extended to address the fiscal realities of sub-state jurisdictions in the United States. Beleaguered in a second-best setting, devolved efficiency becomes a target difficult to hit. We show that when jurisdictions rely on taxing mobile factors and mobile factor productivity is enhanced by relaxing public health mitigation, jurisdictions will choose lower levels of public health quality.
\end{abstract}

JEL classification numbers: H73, I18, R13.

Keywords: Federalism, Decentralized authority, COVID - 19, Public health mandates.

${ }^{1}$ DouglasMitchell Econometric Consulting, Laramie, WY USA.

Article Info: Received: November 24, 2021. Revised: November 302021.

Published online: December 12021. 


\section{Introduction}

On January 31, 2020, United States Health and Human Services Secretary, Alex M. Azar II, declared a public health emergency for the U.S. to aid the nation's healthcare community in responding to COVID-19 disease (CDC 2020). Devolved jurisdictions soon followed. For example, Governor Mike DeWine of Ohio declared a State of Emergency on March 9, 2020 (Order 2020-01D) and Governor Mark Gordon of Wyoming declared a statewide Public Health Emergency on March 13, 2020 (Order 2020-2). All 50 states followed suit. These orders contained language directing state and county health directors to take all appropriate actions to provide aid to locations where there is a threat to public health. On March 26, 2020, POTUS Donald J. Trump and his Coronavirus Taskforce penned a letter aimed at devolving the focus of disease mitigation to the local level.

"My administration is working to publish new guidelines for state and local policymakers to use in making decisions about maintaining, increasing, or relaxing social distancing and all other mitigation measures they have put in place." (from Wilkie 2020)

This quote highlights the important issue of the appropriate role of the various levels of government in the setting of public health regulations (during an emergency or not) and the monitoring and enforcement of these regulations. Regarding COVID19 , mitigation measures in the U.S. take the form of centrally determined guidelines and mandates with the responsibility for implementation generally delegated to provincial governments. Thus, public health policy appears to be a joint governmental activity but the fundamental decision of how stringent restrictions are lie with local authorities. ${ }^{2}$ In this decentralized setting, jurisdictions essentially presume that public health quality is locally contained or more likely they simply ignore any transboundary effects. It is widely accepted that such interjurisdictional externalities are likely to be the source of inefficient outcomes without some type of central government intervention (Oates 2002) or Coasian cooperation (Coase 1960). It appears the U.S. government, for now, is relying on decentralized local authority. The interesting normative issues here center on how different regulation and enforcement is across jurisdictions and will local authorities apply public health protocols in a sub-optimal manner. The latter could give rise to interjurisdictional economic competition.

There are numerous and very public examples of the asymmetric application of national COVID-19 guidelines and mandates across the country (Associated Press 2020, Jenkins 2021, Kincaid and Leckrone 2021, Reeth 2021). In one polar case, many areas within the state of South Dakota claim that COVID-19 restrictions were never implemented or followed and that unemployment, in most of the state, was lower at the beginning of 2021 than before COVID-19 (Davis 2021). Additionally,

2 This response is not unique to the U.S. as most "Federal Countries" world-wide responded with similar intergovernmental interactions (Chattopadhyay, R., et al 2021). 
examples of interjurisdictional competition are emerging with firms fleeing parts of New York and California-areas hit with prohibitive COVID-19 restrictions and mandates (Kelly 2020). Moreover, a mounting sentiment suggests that COVID-19 (and succeeding variants) opened the door for long-term heightened public health awareness and the continuation of varying public health regulations and mandates (see Smith et al vs. State of Wyoming et al 2021). We must, however, exercise some care in drawing out the implications of these many examples. Expectations of whether local authorities will use public health regulations and mandates for competitive purposes going forward depends somewhat on perceptions. If policymakers and owners of firms and/or capital believe that these regulations matter in the long-run, they may well respond accordingly.

There is now a vast literature addressing local fiscal policy that argues that decentralized decision making is not appropriate and results in distorted equalibria (see Baskaran et al 2016 for a recent review). The basic contention in this literature is that in a setting of interjurisdictional economic competition local officials, in their zeal to attract new business investment and create new jobs, will introduce measures to reduce costs to firms in the form of low taxes and/or lax regulatory standards which result in suboptimal outcomes. Such competition has given rise to proposals in the past for federal intervention to "save jurisdictions from themselves" (ACIR 1981). However, if residents of a jurisdiction care about public goods, including public health quality, then economic competition to attract commerce imposes genuine welfare costs on these residents. It is not clear that interjurisdictional competition would rise to the level of being 'destructive'.

The purpose of this paper is to develop a general equilibrium model of competitive jurisdictional choice that may provide insights into the normative issues described above. Using a standard neoclassical model of production combined with a utility maximization hypothesis, jurisdictions choose both tax rates and a level of local public health quality. Incorporating the joint determination of both tax decisions and the choice of public health standards can give rise to some interesting interrelationships between local tax revenues and public health considerations. Additionally, the model is extended to address the fiscal realities of sub-state jurisdictions in the U.S. Beleaguered in a second-best setting, devolved efficiency becomes a target difficult to hit. We show that when jurisdictions rely on taxing mobile factors and mobile factor productivity is enhanced by relaxing public health mitigation, jurisdictions will choose lower levels of public health quality.

\section{The basic model}

The national economy consists of a large number of symmetric competitive jurisdictions $(j=1, \ldots J)$. A single industry produces output (the numeraire) within each jurisdiction and is comprised of identical competitive immobile firms $(N)$ where, $\sum_{j} N_{j}=\bar{N}$, with $\bar{N}$ denoting that firms are fixed in national supply.

In equilibrium, initially, firms earn long run profits of zero. For notational simplicity, without loss of generality, jurisdictional indexing is primarily suppressed from this 
point on. Jurisdictions suitable under this framework would include, for example, counties or large metropolitan areas in the United States. The assumption of symmetric jurisdictions avoids the Tiebout (1956) type inefficiencies incongruously stratified by class, information, wealth or size. Moreover, the model focuses on allocative issues rather than distributive questions. If inefficiencies are shown in a homogeneous setting they are likely to be exacerbated in a heterogeneous framework. Three factors of production are supplied to firms in each jurisdiction. The first factor $(F)$ is fixed to the jurisdiction and is owned equally by the jurisdiction's identical immobile residents $(R)$ where, $R=J / \bar{R}$, with $\bar{R}$ representing the national population. Moreover, each resident owns an equal share $1 / \bar{R}$ of $\bar{N}$ and $\bar{M}$ (defined next). The second factor of production $(M)$ is mobile between and within jurisdictions but is fixed, like firms, in national supply, $\sum M=\bar{M}$. For example, $M$ could represent industrial capital. Following convention in the interjurisdictional competition literature (Kunce and Shogren 2007), the model concentrates on location choices rather than new firm or capital formation and market entry.

A crucial feature of the model is the specification of local public health policy and how it potentially encroaches on productive activity and the provision of public goods. We assume that jurisdictional authorities impose restrictions and mandates in order to maintain a level of public health $(\Phi)$ where higher levels of $\Phi$ correspond to more disease prevalence resulting from less restrictive measures. This third factor enters local production as a non-purchased input. Modeling public health policy in this manner allows us to capture the effects of said policies on public health quality, production output and public goods provision in terms of a single parameter, $\Phi$, that enters both the technology and utility functions. In this devolved setting, jurisdictions essentially presume that public health quality is locally contained or more likely they fail to recognize any jurisdictional spillovers. Locally determined outcomes in the presence of interjurisdictional public health externalities cannot be expected to be efficient. Herein, the model focuses on purely local considerations, incorporating central government intervention or some type of Coasian cooperation could prove to be a fruitful extension for future research.

Let $P(F, M, \Phi)$ denote each jurisdiction's constant-returns-to-scale production technology where each firm produces, $1 / N[P(F, M, \Phi)]$. Further, production possesses all the conventional curvature properties hence all marginal products $P_{F}$, $P_{M} \& P_{\Phi}$ are positive and diminish $P_{F F}, P_{M M} \& P_{\Phi \Phi}<0$, where subscripts denote partial derivatives. The signs of production cross second-partials depends on the relationship of the factors in production. For example, $P_{M \Phi}$, is positive if the mobile factor and public health quality complement (enhance) each other in production. The stock of the mobile factor is distributed in accordance to profit maximization which implies that the return to the mobile factor $(m)$, net of taxes, will be equated across all jurisdictions. All jurisdictions are considered 'small' in the sense that $m$ is viewed as an exogenous parameter. The mobile factor receives its marginal product, 
net of a unit tax $\tau$, where the stock of the mobile factor will adjust satisfying the profit maximizing condition,

$$
m=P_{M}-\tau
$$

Each jurisdiction raises tax revenues for local Samuelsonian (Samuelson 1954, $1955)$ public goods $(G)$ by taxing the fixed and mobile factors separately given,

$$
G=t F+\tau M
$$

Equation (2) assumes that 'small' jurisdictions possess the authority to impose this tax structure. From the linear homogeneity of production, immobile factor owners (residents) earn income returns $(X)$ according to,

$$
X=y+\frac{1}{R}[P(F, M, \Phi)-m M-G]
$$

where $y$ represents any exogenous income, for example net returns from mobile factor ownership. ${ }^{3}$

Each identical resident receives utility from income, local public goods and public health quality levels. Because public health quality depends on the jurisdiction's choice of restrictions, mandates and the resulting level of $\Phi$, utility becomes,

$$
U=U(X, G, \Phi)
$$

where $U$ is a quasi-concave function, marginal utilities' of income and public goods are increasing, and the marginal utility of $\Phi$ is negative. Accordingly, the partial derivatives are $U_{X}>0, U_{G}>0$ and $U_{\Phi}<0$. Higher $\Phi$ corresponds to poorer public health quality where $\Phi$ represents a pure public bad. In keeping with the Arrow-Debreu (Wilson 1995) separation assumption for general equilibrium constructs, residents have two distinct roles in the model. First, as consumers, they seek to maximize utility over a bundle of goods and services. Second, supplying production inputs and in return receiving income returns. More of the mobile factor and lax public health restrictions enhance local production and can provide residents with higher incomes. However, in order to attract the mobile factor, the jurisdiction lowers the tax on the mobile factor (effecting $G$ ) and/or relaxes public health regulations (lowering utility directly) thus setting up a characteristic economic tradeoff.

It is recognized that perfect competition among firms leads to efficient outcomes, herein we are interested if competition among jurisdictions also leads to efficiency.

${ }^{3}$ For example $y=(m \bar{M}) / \bar{R}$. 
Since all residents in the model are identical, we can reduce the analysis in focus to any representative resident. Efficiency requires the maximization of a representative resident's utility in one jurisdiction subject to (i) resident's utility in all other jurisdictions is equalized to a fixed level, (ii) aggregate production and consumption clear, and (iii) the mobile factor stock is allocated entirely among jurisdictions (clears). The resulting social optimum conditions are well known (see Oates 1972, 2002) therefore derivation discussion in this section is keep to a minimum. Ignoring any corner solutions, efficiency becomes,

$$
\begin{aligned}
& R \frac{U_{G}}{U_{X}}=1 \quad \forall j, \\
& R \frac{-U_{\Phi}}{U_{X}}=P_{\Phi} \quad \forall j, \\
& P_{M}^{j}=P_{M}^{i} \quad \forall j, i \quad j \neq i .
\end{aligned}
$$

Equation (5) represents the familiar 'Samuelson condition' for the provision of public goods (Wilson 1986). This appropriate optimality condition suggests that the sum of the marginal rates of substitution $\left(\Sigma M R S_{G, X}\right)$ between the public good and income (over all jurisdictional residents) equals the marginal cost of providing an incremental increase in the public good. Given equations (2) and (3), the marginal cost in this context is one for one. Equation (6) shows that the jurisdiction should choose a combination of income and public health quality such that the sum of the marginal rates of substitution between the two equals the marginal product of public health. Equation (6) represents a Samuelson rule for public health quality, if you are so inclined. Equation (7) shows the optimal clearing condition for the mobile production factor.

The normative question to be answered is whether there is any systematic penchant for local authorities to choose other than optimal levels of $t, \tau$ and $\Phi$. Given that jurisdictional residents are identical, assume that a benevolent local authority maximizes the representative resident's utility given by equation (4) over the choice variables $t, \tau$ and $\Phi$ subject to the constraint equations (2) and (3). The general first order conditions in total differential form become,

$$
U_{X} \mathrm{~d} X+U_{G} \mathrm{~d} G+U_{\Phi} \mathrm{d} \Phi=0,
$$

where,

$$
\mathrm{d} X=\frac{1}{R}\left[P_{F} \mathrm{~d} F+P_{M} \mathrm{~d} M+P_{\Phi} \mathrm{d} \Phi-(m \mathrm{~d} M+M \mathrm{~d} m)-\mathrm{d} G\right],
$$


and,

$$
\mathrm{d} G=t \mathrm{~d} F+F \mathrm{~d} t+\tau \mathrm{d} M+M \mathrm{~d} \tau .
$$

Recall that $F$ and $m$ are both fixed in the jurisdiction's point of view. Evaluating the first order conditions with respect to $t$ holding the other choice variables constant yields,

$$
U_{X}\left[-\frac{1}{R} \frac{\mathrm{d} G}{\mathrm{~d} t}\right]+U_{G}\left[\frac{\mathrm{d} G}{\mathrm{~d} t}\right]+U_{\Phi}[0]=0,
$$

or,

$$
\left[R \frac{U_{G}}{U_{X}}-1\right] \frac{\mathrm{d} G}{\mathrm{~d} t}=0, \text { where } \frac{\mathrm{d} G}{\mathrm{~d} t}=F
$$

Equation (11) shows that taxing the fixed factor insures efficient provision of local public goods as found in equation (5) (Kunce and Shogren 2008). Evaluating the first order conditions with respect to $\tau$ gives,

$$
U_{X}\left[\frac{1}{R}\left(\tau \frac{\mathrm{d} M}{\mathrm{~d} \tau}-\frac{\mathrm{d} G}{\mathrm{~d} \tau}\right)\right]+U_{G}\left[\frac{\mathrm{d} G}{\mathrm{~d} \tau}\right]+U_{\Phi}[0]=0,
$$

or,

$$
\left[R \frac{U_{G}}{U_{X}}-1\right]\left[\frac{\mathrm{d} G}{\mathrm{~d} \tau}\right]+\tau \frac{\mathrm{d} M}{\mathrm{~d} \tau}=0
$$

Using equation (11) where $R\left(U_{G} / U_{X}\right)=1$, the evaluation of equation (12) rests on the comparative static $\mathrm{d} M / \mathrm{d} \tau$. The ratio of two differentials is interpreted as a partial derivative when holding all other variables constant. Equation (1) provides the optimality condition necessary to compute this comparison using the implicit function theorem where,

$$
\begin{aligned}
& E_{1}: P_{M}-\tau-m=0 \\
& \frac{\mathrm{d} M}{\mathrm{~d} \tau}=-\frac{\partial E_{1} / \partial \tau}{\partial E_{1} / \partial M}=\frac{1}{P_{M M}}<0 .
\end{aligned}
$$

Equations (11) and (13) forces $\tau=0$ in equation (12); jurisdictions choose not to tax the mobile factor in the presence of the first-best fixed factor tax. Lastly, evaluating the first order conditions with respect to $\Phi$ yields, 


$$
U_{X}\left[\frac{1}{R}\left(\tau \frac{\mathrm{d} M}{\mathrm{~d} \Phi}+P_{\Phi}-\frac{\mathrm{d} G}{\mathrm{~d} \Phi}\right)\right]+U_{G}\left[\frac{\mathrm{d} G}{\mathrm{~d} \Phi}\right]+U_{\Phi}[1]=0,
$$

or,

$$
\left[R \frac{U_{G}}{U_{X}}-1\right] \frac{\mathrm{d} G}{\mathrm{~d} \Phi}+\left(\tau \frac{\mathrm{d} M}{\mathrm{~d} \Phi}\right)+R \frac{U_{\Phi}}{U_{X}}+P_{\Phi}=0 .
$$

Using equation (11) and because $\tau=0$ from equation (12), equation (14) reduces to the socially efficient solution found in equation (6). Jurisdictional maximization behavior implies that the local authority will set $\Phi$ so that the change in income equals the marginal willingness to pay for public health quality, $-R\left(U_{\Phi} / U_{X}\right)$. It is important to note that the choice of public health quality and the local public goods sector are closely intertwined. In the presence of first-best tax instruments, local choice is socially efficient. Moreover, jurisdictional efficiency is conditioned on the internalization of public health rents. Linear homogeneity of production yields public health rents, $P_{\Phi} \Phi$, which are captured by local residents through their income assumption in equation (3). This latter assumption parallels, implicitly, a perfect Pigovian remedy (Pigou 1932).

\section{Realities of sub-state jurisdictions}

Generally, first-best instruments are not authorized or available to 'small' communities in the United States. Roughly 72 percent of local government's tax revenues are sourced from property taxation (Urban-Brookings Tax Policy Center 2017). The use of sophisticated Pigovian mechanisms are rare and generally are endeavors of national governments. Additionally, separating local public good provision from actions to internalize public health rents is simply unrealistic at the devolved level. If jurisdictions rely on property taxation to fund public goods, they will likely use these same instruments in efforts to capture externality rents.

Facing these limiting realities, we augment the model in two ways. First, financing local public goods and attempts to capture public health rents are facilitated using mobile factor taxation where,

$$
G=\tau M .
$$

This approach is convention in the vast fiscal federalism and tax competition literature because local governments generally believe that private production is sufficiently capital intensive and aggressively pursue this crucial input using inefficient tax policies (see Wilson 1999). Second, firms are now perfectly mobile, seek public health rents and will locate where they can maximize them,

$$
\pi=\frac{1}{N} P_{\Phi} \Phi
$$


where equilibrium is achieved when rents are equalized across jurisdictions. Competitive firms and jurisdictions view $\pi$ as exogenous. After firms choose a location, they employ the mobile factor according to equation (1). Additionally, firms employ the fixed factor where exogenous and endogenous income returns to owner residents becomes,

$$
X=y+\frac{1}{R}[P(F, M, \Phi)-m M-\pi N-G]
$$

where $y$ represents, again, any exogenous income (e.g. returns to mobile factor and firm ownership). ${ }^{4}$

Again, assume that a benevolent local authority maximizes the representative resident's utility given in equation (4) over the choice variables $\tau$ and $\Phi$ subject to the constraint equations (15) and (17). The general first order conditions in total differential form are found in equation (8) and require,

$$
\mathrm{d} X=\frac{1}{R}\left[P_{F} \mathrm{~d} F+P_{M} \mathrm{~d} M+P_{\Phi} \mathrm{d} \Phi-(m \mathrm{~d} M+M \mathrm{~d} m)-(\pi \mathrm{d} N+N \mathrm{~d} \pi)-\mathrm{d} G\right]
$$

and,

$$
\mathrm{d} G=\tau \mathrm{d} M+M \mathrm{~d} \tau
$$

Recall that $F, m$ and $\pi$ are all fixed in the jurisdiction's point of view. Evaluating the first order conditions with respect to $\tau$ yields,

$$
U_{X}\left[\frac{1}{R}\left(\tau \frac{\mathrm{d} M}{\mathrm{~d} \tau}-\pi \frac{\mathrm{d} N}{\mathrm{~d} \tau}-\frac{\mathrm{d} G}{\mathrm{~d} \tau}\right)\right]+U_{G}\left[\frac{\mathrm{d} G}{\mathrm{~d} \tau}\right]+U_{\Phi}[0]=0,
$$

or,

$$
\left[R \frac{U_{G}}{U_{X}}-1\right] \frac{\mathrm{d} G}{\mathrm{~d} \tau}+\tau \frac{\mathrm{d} M}{\mathrm{~d} \tau}-\pi \frac{\mathrm{d} N}{\mathrm{~d} \tau}=0
$$

Evaluating the first order conditions with respect to $\Phi$ gives,

$$
U_{X}\left[\frac{1}{R}\left(\tau \frac{\mathrm{d} M}{\mathrm{~d} \Phi}+P_{\Phi}-\pi \frac{\mathrm{d} N}{\mathrm{~d} \Phi}-\frac{\mathrm{d} G}{\mathrm{~d} \Phi}\right)\right]+U_{G}\left[\frac{\mathrm{d} G}{\mathrm{~d} \Phi}\right]+U_{\Phi}[1]=0
$$

or,

${ }^{4}$ For example $y=(m \bar{M}+\pi \bar{N}) / \bar{R}$. 


$$
\left[R \frac{U_{G}}{U_{X}}-1\right] \frac{\mathrm{d} G}{\mathrm{~d} \Phi}+R \frac{U_{\Phi}}{U_{X}}+P_{\Phi}+\tau \frac{\mathrm{d} M}{\mathrm{~d} \Phi}-\pi \frac{\mathrm{d} N}{\mathrm{~d} \Phi}=0
$$

Evaluation of this pair of first-order-conditions appears more complex than those derived in section 2 above. First, using equation (19), the differential $\mathrm{d} G$ needs to be evaluated for both choice variables $\tau$ and $\Phi$. Additionally, equations (1) and (16) provide the necessary system to determine all comparative statics examining changes in $M$ and $N$ with respect to $\tau$ and $\Phi$. Consider the following implicit function matrix systems,

$$
\begin{aligned}
& {\left[\begin{array}{cc}
P_{M M} & 0 \\
\frac{1}{N} \Phi P_{M \Phi} & -\frac{1}{N^{2}} \Phi P_{\Phi}
\end{array}\right]\left[\begin{array}{l}
\frac{\mathrm{d} M}{\mathrm{~d} \tau} \\
\frac{\mathrm{d} N}{\mathrm{~d} \tau}
\end{array}\right]=-\left[\begin{array}{c}
-1 \\
0
\end{array}\right],} \\
& {\left[\begin{array}{cc}
P_{M M} & 0 \\
\frac{1}{N} \Phi P_{M \Phi} & -\frac{1}{N^{2}} \Phi P_{\Phi}
\end{array}\right]\left[\begin{array}{l}
\frac{\mathrm{d} M}{\mathrm{~d} \Phi} \\
\frac{\mathrm{d} N}{\mathrm{~d} \Phi}
\end{array}\right]=-\left[\begin{array}{c}
P_{M \Phi} \\
\frac{1}{N}\left(\Phi P_{\Phi \Phi}+P_{\Phi}\right)
\end{array}\right],}
\end{aligned}
$$

which yields equation (13) and,

$$
\begin{aligned}
\frac{\mathrm{d} N}{\mathrm{~d} \tau} & =\frac{N P_{M \Phi}}{P_{\Phi} P_{M M}}, \\
\frac{\mathrm{d} M}{\mathrm{~d} \Phi} & =\frac{P_{M \Phi}}{-P_{M M}}, \\
\frac{\mathrm{d} N}{\mathrm{~d} \Phi} & =\frac{N\left[\Phi\left(P_{M \Phi}\right)^{2}-P_{M M}\left(\Phi P_{\Phi \Phi}+P_{\Phi}\right)\right]}{-\Phi P_{\Phi} P_{M M}} .
\end{aligned}
$$

A discussion of the comparative statics just derived is warranted. Equation (13) shows that, under the profit maximization hypothesis, a higher tax rate in a jurisdiction repels the mobile factor. Equation (22) shows how firms respond to taxes on the mobile factor. When the mobile factor and public health quality are technical complements, $P_{M \Phi}>0$, firms are repelled from jurisdictions with higher mobile factor taxes. In equation (23), if the mobile factor and public health quality are complements, the mobile factor will locate where public health restrictions are more lax. Recall that jurisdictions with fewer public health restrictions and 
mandates increase the level of $\Phi$. Lastly, equation (24) depicts how firms respond to changes in public health quality. The sign of equation (24) rests on how jurisdictional public health rents respond to a change in $\Phi$,

$$
\frac{\mathrm{d}\left(\Phi P_{\Phi}\right)}{\mathrm{d} \Phi}=\Phi P_{\Phi \Phi}+P_{\Phi}
$$

If equation (25) is positive ( $P_{\Phi \Phi}$ is sufficiently small), equation (24) is then positive - firms favor jurisdictions with higher public health rents hence lax restrictions. This appears as a natural assumption.

The utility maximization solution requires equations (20) and (21) to be solved simultaneously. Using equation (19) evaluated for $\tau$ and $\Phi$ and the comparative static equations (13), (22) - (24) yields the reduced form by suitable rearrangement,

$$
R \frac{-U_{\Phi}}{U_{X}}=P_{\Phi}+P_{M \Phi} M\left(R \frac{U_{G}}{U_{X}}-1\right)-\pi N\left(\frac{\Phi P_{\Phi \Phi}+P_{\Phi}}{\Phi P_{\Phi}}\right),
$$

where the last two terms to the far right of equation (26) represent the 'wedge' (difference) from social efficiency shown in equation (6). If this wedge is positive (negative), $\Phi$ will be set higher (lower) than the social optimum. The second term to the right of the equal sign represents the 'fiscal effect' imposed by second-best tax instruments. Recall that if first-best taxation is authorized and available, this term vanishes in equilibrium.

Taxing a mobile factor generally leads to under provision of local public goods (Wilson 1986, 1999). Jurisdictions recognize that raising the tax rate $\tau$ to finance public goods will repel the taxed mobile factor. However, they fail to acknowledge this positive externality they confer to other jurisdictions and thus underprovide their own public goods. The last term on the far right of equation (26) is the 'profit effect' which represents the loss of public health rents to firms that are owned mostly outside a single jurisdiction.

Proposition 1. Assuming jurisdictions rely on second-best mobile factor taxation (e.g. property taxation), local public goods are underprovided $R\left(U_{G} / U_{X}\right)>1$, the mobile factor and public health quality are technical complements in production, public health rents increase when regulations and mandates are relaxed, and the fiscal effect is sufficiently large - jurisdictions will possess incentives to relax public health restrictions and mandates and set $\Phi$ above social efficient levels.

A crucial implication of proposition 1 is that reliance on second-best tax structures affects the choice of public health quality. First-best local taxation removes incentives to pursue the mobile factor with inefficient tax and public expenditure 
policies, however, even if the fiscal effect vanishes in equation (26) the profit effect remains.

Proposition 2. Assuming jurisdictions tax immobile residents to provide public goods efficiently $R\left(U_{G} / U_{X}\right)=1$ and public health rents increase when regulations and mandates are relaxed - local authorities will set $\Phi$ lower than the social optimum.

The negative signed profit effect represents public health rents leaking to firms owned mostly outside the jurisdiction. In Proposition 2 local authorities now possess incentives to set more restrictive public health measures (lower $\Phi$ ). Here residents are fully effected by public health choices yet share little of the rents. Taxing local factors fails to provide jurisdictions an efficient rent collection instrument. This inefficient equilibrium is akin to an overprotection result. Only Pigovian remedies will realign this overprotection equilibrium with social efficiency.

\section{Concluding remarks and future extensions}

In presenting a model with homogeneous jurisdictions, purely localized public health considerations, public choices that maximize residents' welfare and fully understanding the second-best realities of sub-state jurisdictions - decentralized efficiency remains a target difficult to hit. Conceding that devolved decision-making involves inefficiencies, even under the best of light, the motivations of federal authorities regarding COVID-19 mitigation emerge as puzzling. It is true that decentralization can provide a valuable aspect in policy advancement by offering the opportunity for experimentation with differing approaches to regulatory management (Oates 2002). Under so-called 'laboratory federalism', there are potential gains from learning by doing so that we can find out how certain kinds of policy measures work in practice without imposing untested systems on the entire country. Moreover, a variety of approaches to regulatory management across jurisdictions can likely uncover previously unknown methods or policy instruments. In any case, the last two years certainly feels like a considerable natural experiment.

Regarding extensions and future research, jurisdictional spillovers must be addressed. Centralized uniform public health standards, in general, have been shown to be mostly ineffective with COVID-19 where spillovers are evident (Kincaid and Leckrone 2021). Such inefficient outcomes can also emerge in situations where jurisdictions are not 'small' and play a strategic game with other jurisdictions. Borrowing a chapter from the environmental literature, List and Mason (2001) have examined dynamic game-theoretic models with asymmetric players to assess welfare implications in a setting with transboundary pollution. Specifically, they examine two policy alternatives: a decentralized cooperative setting with differing standards and a centrally determined uniform standard. 
Simulations of the model show that the devolved cooperative setting can dominate a centrally determined uniform standard if there are significant asymmetries across jurisdictions and if initial levels of pollution are not too high. Accordingly, jurisdictional cooperation offers the potential for a more efficient Coasian type of resolution for public health transboundary effects and therefore should be explored.

\section{References}

[1] Centers for Disease Control CDC (2020). https://www.cdc.gov/media/releases/2020.

[2] Wilkie, C. (2020). Trump plan calls for classifying Coronavirus risk county by county. March 26, 2020. NBC News. http://www.nbcnews.com.

[3] Chattopadhyay, R., Knüpling, F. and Whittington, L. (2021). An introduction to COVID-19 and federalism, in Federalism and the Response to COVID-19: A Comparative Analysis, Eds: R. Chattopadhyay, F. Knüpling, D. Chebenova, L. Whittington and P. Gonzalez, Routledge Taylor \& Francis Group: New York, pp. 1-6.

[4] Oates, W. (2002). A reconsideration of environmental federalism, in Recent Advances in Environmental Economics, Eds: J. A. List and A. de Zeeuw, Edward Elgar Publishing: UK, pp. 1-32.

[5] Coase, R. (1960). The problem of social costs. The Journal of Law and Economics 3, pp. 1-44.

[6] Associated Press (2020). COVID-19 responses vary nationwide. December 13, 2020. http://www.usnews.com.

[7] Jenkins, C. (2021). Another Florida county approves mask mandate in defiance of [Gov.] DeSantis. The Hill, September 1. 2021. http://www.thehill.com.

[8] Kincaid, J. and Leckrone, J. (2021). COVID-19 and American federalism: First wave responses, in Federalism and the Response to COVID-19: A Comparative Analysis, Eds: R. Chattopadhyay, F. Knüpling, D. Chebenova, L. Whittington and P. Gonzalez, Routledge Taylor \& Francis Group: New York, pp. 239-249.

[9] Reeth, M. (2021). Seven companies that went bankrupt due to COVID-19. U.S. News and World Report. March 11, 2021. http://www.usnews.com.

[10] Davis, J. (2021). South Dakota rejected lockdowns and mask orders. The Western Journal, January 24, 2021. http://www.thewesternjournal.com.

[11] Kelly, J. (2020). Wall street banks and tech companies are fleeing New York and California. Forbes, December 14, 2020. http://www.forbes.com.

[12] Ms Grace Smith et al vs. State of Wyoming et al. (2021). U.S. District Court for the District of Wyoming. Case 2021cv00201. Filed November 2, 2021.

[13] Baskaran, T., Feld, L. and Schnellenbach, J. (2016). Fiscal federalism, decentralization and economic growth: A meta-analysis. Economic Inquiry 54(3), pp. 1445-1463.

[14] Advisory Commission on Intergovernmental Relations ACIR (1981). Regional growth: Interstate tax competition. Washington, DC. 
[15] Tiebout, C. (1956). A pure theory of local expenditures. The Journal of Political Economy, 64 (5), pp. 416-424.

[16] Kunce, M. and J. Shogren. (2007). Destructive interjurisdictional competition: Firm, capital, and labor mobility in a model of direct emission control. Ecological Economics 60(3), pp. 543-549.

[17] Samuelson, P. (1954). The pure theory of public expenditure. The Review of Economics and Statistics (36)4, pp. 387-389.

[18] Samuelson, P. (1955). Diagrammatic exposition of a theory of public expenditure. The Review of Economics and Statistics (37)4, pp. 350-356.

[19] Wilson, J. (1995). Mobile labor, multiple tax instruments and tax competition. Journal of Urban Economics 38, pp. 333-356.

[20] Oates, W. (1972). Fiscal Federalism. Harcourt Brace Jovanovich, New York.

[21] Wilson J. (1986). A theory of interregional tax competition. Journal of Urban Economics 19, pp. 296-315.

[22] Kunce, M. and J. Shogren. (2008). Efficient decentralized fiscal and environmental policy: A dual purpose Henry George tax. Ecological Economics 65(3), pp. 569-573.

[23] Pigou, A. (1932). The Economics of Welfare. Fourth Ed. MacMillan and Co. Limited. London, UK.

[24] Urban-Brookings Tax Policy Center. (2017). State and local finance initiative data query system. http://www.taxpolicycenter.org.

[25] Wilson, J. (1999). Theories of tax competition. National Tax Journal 52, pp. 269-304.

[26] List, J. and Mason, C. (2001). Optimal institutional arrangements for transboundary pollutants in a second-best world: Evidence from a differential game with asymmetric players. Journal of Environmental Economics and Management 42, pp.277-296. 